\title{
Article \\ Novel Fabrication of Silver-Coated Copper Nanowires with Organic Compound Solution
}

\author{
Suhyun Lee, Chien Wern $(\mathbb{D}$ and Sung Yi * \\ Department of Mechanical and Materials Engineering, Portland State University, Portland, OR 97207-075, USA; \\ suhyun@pdx.edu (S.L.); wernc@pdx.edu (C.W.) \\ * Correspondence: syi@pdx.edu
}

Citation: Lee, S.; Wern, C.; Yi, S Novel Fabrication of Silver-Coated Copper Nanowires with Organic Compound Solution. Materials 2022 15, 1135. https://doi.org/10.3390/ ma15031135

Academic Editors: Wojciech J. Stępniowski and Antonio Polimeni

Received: 2 December 2021 Accepted: 21 January 2022 Published: 1 February 2022

Publisher's Note: MDPI stays neutral with regard to jurisdictional claims in published maps and institutional affiliations.

Copyright: (C) 2022 by the authors. Licensee MDPI, Basel, Switzerland. This article is an open access article distributed under the terms and conditions of the Creative Commons Attribution (CC BY) license (https:// creativecommons.org/licenses/by/ $4.0 /)$.

\begin{abstract}
Copper nanowires and $\mathrm{Cu}-\mathrm{Ag}$ nanowires have various potential applications, such as transparent conductive film, flexible electronics, and conductive filler. In this study, we developed a new green fabrication method for silver-coated copper nanowires using methylsulfonylmethane $\left(\mathrm{DMSO}_{2}\right)$, which is an environmentally friendly chemical at the food-grade level, to replace toxic chemicals, including ammonia, in the silver coating process. Copper nanowires were synthesized under various reaction temperatures and concentrations of hydrazine $\left(\mathrm{N}_{2} \mathrm{H}_{4}\right)$, ethylenediamine (EDA), sodium hydroxide $(\mathrm{NaOH})$, and copper precursor. The reaction temperature higher than $70{ }^{\circ} \mathrm{C}$ caused the oxidation of copper products and evaporation of the sample solution. The optimal conditions to synthesize copper nanowires more than $18 \mu \mathrm{m}$ in length and 25-45 $\mathrm{nm}$ in diameter were determined: $9 \mathrm{M}$ of $\mathrm{NaOH}, 50 \mu \mathrm{L}$ of EDA, $17 \mathrm{mM}$ of $\mathrm{CuCl}_{2}, 5.7 \mathrm{mM}$ of $\mathrm{N}_{2} \mathrm{H}_{4}$, and $70{ }^{\circ} \mathrm{C}$ reaction temperature. $\mathrm{Cu}-\mathrm{Ag}$ nanowires, which have about a $12 \mathrm{~nm}$ thick silver shell, were successfully fabricated at room temperature under $1 \mathrm{mM}$ of silver nitrate $\left(\mathrm{AgNO}_{3}\right)$ and $1 \mathrm{wt} \%$ of $\mathrm{DMSO}_{2}$. Synthesis conditions for copper and silver-coated copper nanowires have been optimized.
\end{abstract}

Keywords: synthesis; nanowires; copper nanowires; silver coating; core-shell nanowires; $\mathrm{Cu}-\mathrm{Ag}$ nanowires

\section{Introduction}

Transparent electrodes are essential components for flat-panel displays, touch screens, solar cells, and flexible electronics such as foldable tablets and phones, bendable lighting emitting diodes (LEDs), and wearable sensors. Indium tin oxide (ITO) is widely used to fabricate transparent conductors because of its high conductivity, low resistance, and high transmittance [1]. However, ITO is brittle, expensive, and has poor reserves on Earth [2]. When ITO is used on flexible electronics, the substrate can crack when bending or stretching is applied. In addition, it is difficult to produce at a low cost and large scale because of its scarcity [3].

To overcome the limitations of this conventional material, the synthesis of 2D copper nanosheets has intensively been researched in previous work [4]. Several other nanomaterials, including 1D carbon nanotubes (CNTs), graphene, and 1D metal nanowires, have also been considered as alternatives $[5,6]$. Those nanomaterials can achieve flexibility; however, the sheet resistance of CNTs $(150 \Omega / \mathrm{sq})$ and graphene $(250 \Omega / \mathrm{sq})$ is higher than that of ITO (20 $\Omega$ /sq) [7,8]. Because of their higher sheet resistance, metal nanowires are considered promising alternative materials. Among various metal nanowires, the sheet resistance of silver $(10 \Omega / \mathrm{sq})$ and copper $(34.8 \Omega / \mathrm{sq})$ nanowires meets the property required to be comparable with ITO [9]. Copper nanowires receive more attention than silver nanowires. This is because copper not only has the second-highest conductivity and lowest resistivity, but also has extremely high reserves [10-12]. In addition, the stretchable reliability of copper nanowires has been demonstrated through the test of repeated stretching and releasing on wearable stretchable sensors, showing current stability and high sensitivity [6]. 
To synthesize copper nanowires, researchers have attempted several methods, such as chemical vapor deposition [13,14], vacuum thermal decomposition [15], the template-based method [16,17], and the solution-based method [18,19]. The chemical vapor deposition method and vacuum thermal decomposition method require a processing temperature over $200{ }^{\circ} \mathrm{C}$, and the template-based method requires complex electrode preparation. On the other hand, the solution-based method has a simple procedure with a relatively low processing temperature compared to chemical vapor deposition and vacuum thermal decomposition. Moreover, it is possible to control the quality of copper nanowires during the reaction time [20].

The solution-based method is mainly carried out by controlling the number of copper precursor ions to obtain pure copper nanowires. The synthesis of copper nanowires by the solution-based method consists of a reagent, copper precursor, capping agent, and reducing agent. Li et al. [21] synthesized copper nanowires using oleylamine and glucose as a capping agent and a reducing agent, respectively, with the length of 60-90 $\mu \mathrm{m}$ and the diameter of $45 \pm 3 \mathrm{~nm}$. However, it required a long reaction time of $12 \mathrm{~h}$ and a high reaction temperature of $116^{\circ} \mathrm{C}$. In addition, using oleylamine as a capping agent requires combining it with other capping agents such as oleic acid and potassium bromide (KBr) [22]. Chang et al. [18] researched the synthesis of copper nanowires by using ethylenediamine (EDA) as a capping agent and hydrazine $\left(\mathrm{N}_{2} \mathrm{H}_{4}\right)$ as a reducing agent. They obtained copper nanowires that are 40-50 $\mu \mathrm{m}$ in length and 90-120 $\mathrm{nm}$ in diameter at $60^{\circ} \mathrm{C}$. Rathmell et al. [19] implemented the approach based on Chang et al. [18] at a larger scale to obtain $1.2 \mathrm{~g}$ of copper nanowires having the length of $10 \pm 3 \mu \mathrm{m}$ and the diameter of $90 \pm 10 \mathrm{~nm}$ at the processing temperature of $80{ }^{\circ} \mathrm{C}$ for $1 \mathrm{~h}$. Such copper nanowires were grown from spherical nanoparticles found at the end of copper nanowires. Koo et al. [23] demonstrated the relationship between EDA and copper nanowire oxidation. EDA plays a role in reducing hydroxide adsorption, which increases the resistivity of copper nanowire oxidation.

Copper nanowires are very vulnerable to contact with oxygen, which causes the formation of an oxide layer on the surface and a subsequent reduction in electrical conductivity [24]. In addition, the irregular surface of the copper nanowires is susceptible to defects, which would cause dangling chemical bonds on the surface of the copper nanowires. This chemical bond results in the oxidation of the copper nanowires, reducing surface energy [25]. The formation of an oxidation-resistant metallic shell on the surface of the copper nanowires is considered an effective way to enhance oxidation resistance. Among metals, nickel $(\mathrm{Ni})$, platinum $(\mathrm{Pt})$, gold $(\mathrm{Au})$, and silver $(\mathrm{Ag})$ are suitable shell materials because of their low resistivity and high electrical conductivity. In particular, if silver is used as a shell material and silver oxide is formed on the surface of copper nanowires, it has much higher electrical conductivity than copper oxide [26].

To fabricate core-shell nanowires, the electroplating method and the galvanic replacement method are generally used. The electroplating method prevents metal shell deposition from aggregating and is used for a wide range of metals including $\mathrm{Ni}$, Pt, and $\mathrm{Au}$. However, this method has low efficiency as it does not uniformly plate the entire copper nanowires [27]. The galvanic replacement method provides simple and diverse multifunctional nanostructures. However, breakage of copper nanowires can be caused when plating a metal with a higher reduction potential than copper due to corrosion and oxidation [28].

Niu et al. [29] conducted the fabrication of $\mathrm{Cu}$-Au nanowires through the growth of the atomic layer of Au precursor. Chen et al. [30] used the electroplating method to obtain $\mathrm{Cu}-\mathrm{Pt}$ nanowires. Those nanowires demonstrated oxidation stability under the ambient condition of long-period exposure. However, $\mathrm{Au}$ and $\mathrm{Pt}$ are precious and expensive metals, so these nanowires are expensive. Luo et al. [26] and Jiang et al. [31] developed well-dispersed silver nanoparticles on the surface of copper nanowires using the galvanic replacement method in the presence of ammonium hydroxide $\left(\mathrm{NH}_{4} \mathrm{OH}\right)$. Dissolved silver in the $\mathrm{NH}_{4} \mathrm{OH}$ solution reacted with the copper atom that brought about the deposition of silver nanoparticles on 
the surface of copper nanowires. The weight of $\mathrm{Cu}-\mathrm{Ag}$ nanowires increased at a higher temperature exposure than copper nanowires, and the total increasing rate of $\mathrm{Cu}-\mathrm{Ag}$ nanowires was about eight times higher than that of copper nanowires [26]. While the sheet resistance of the copper nanowire film exposed at $160^{\circ} \mathrm{C}$ increased rapidly within a few hours, the sheet resistance of the $\mathrm{Cu}-\mathrm{Ag}$ nanowire film was stable for more than 1 day, with no significant difference compared with silver nanowires [32]. Furthermore, a $5 \mathrm{~nm}$ thick silver shell exhibited a similar sheet resistance value as silver nanowires at $160{ }^{\circ} \mathrm{C}$ for $24 \mathrm{~h}$. The oxidation of copper nanowires could not be prevented at $85^{\circ} \mathrm{C} / 85 \%$ relative humidity, whereas the $15 \mathrm{~nm}$ thick silver shell copper nanowire was stable [33].

The present study is focused on developing the fabrication of silver-coated copper nanowires and a preparation method to replace ammonia through an electroless solutionbased method. A new green fabrication method for $\mathrm{Cu}-\mathrm{Ag}$ nanowires is developed using $\mathrm{DMSO}_{2}$, which is an environmentally friendly chemical at the food-grade level, to substitute ammonia in the silver coating process. $\mathrm{DMSO}_{2}$ has not been reported previously for the fabrication of core-shell nanowires. The effects of different reaction temperatures and concentrations of $\mathrm{N}_{2} \mathrm{H}_{4}, \mathrm{EDA}, \mathrm{NaOH}$, and copper precursor on the morphology of copper nanowires are compared and analyzed. In addition, silver nitrate $\left(\mathrm{AgNO}_{3}\right)$ is employed as a shell material to coat the surface of copper nanowires. Copper nanowires and $\mathrm{Cu}-\mathrm{Ag}$ nanowires are characterized by scanning electron microscopy (SEM) and transmission electron microscopy (TEM).

\section{Materials and Methods}

\subsection{Materials}

To synthesize copper nanowires, a reagent, copper precursor, a capping agent, and a reducing agent are required. Sodium hydroxide $(\mathrm{NaOH})$ was employed as a reagent to decompose copper precursors at the beginning of the procedure. Copper chloride $\left(\mathrm{CuCl}_{2}\right)$ was utilized as a copper precursor. Ethylenediamine (EDA, $\mathrm{C}_{2} \mathrm{H}_{8} \mathrm{~N}_{2}, 99.5 \%$, Sigma-Aldrich, Burlington, $\mathrm{MA}$, USA) and hydrazine $\left(\mathrm{N}_{2} \mathrm{H}_{4}, 35 \mathrm{wt} \%\right.$ in $\mathrm{H}_{2} \mathrm{O}$, Sigma-Aldrich, Burlington, MA, USA) were used as a capping agent and a reducing agent, respectively. To fabricate $\mathrm{Cu}-\mathrm{Ag}$ nanowires, silver nitrate $\left(\mathrm{AgNO}_{3}\right)$ was consumed as aa shell material to coat on the surface of copper nanowires, and methylsulfonylmethane $\left(\mathrm{DMSO}_{2},>99.8 \%\right.$, Bergstrom Nutrition, Vancouver, WA, USA) was used as a copper surfactant and a silver reducing agent. Deionized water $\left(\mathrm{DI} \mathrm{H}_{2} \mathrm{O}\right.$ ) was used as a solvent to dissolve $\mathrm{NaOH}, \mathrm{CuCl}_{2}, \mathrm{AgNO}_{3}$, and $\mathrm{DMSO}_{2}$ and to dilute $\mathrm{N}_{2} \mathrm{H}_{4}$.

\subsection{Method for Synthesis of Copper Nanowires}

The solution-based method was employed to synthesize copper nanowire. All experiments were carried out under $300 \mathrm{rpm}$ magnetic stirring to reach a homogenous state. An Erlenmeyer flask with the material solution was placed in the water bath to keep the constant reaction temperature $\left(40,50,60,70,80,90^{\circ} \mathrm{C}\right)$ for $2 \mathrm{~h}$ reaction time. $\mathrm{NaOH}(4.8$, $5,7,9,12$, and $14.7 \mathrm{M}), \mathrm{CuCl}_{2}(17$ and $37 \mathrm{mM})$, and $\mathrm{N}_{2} \mathrm{H}_{4}(1.7$ and $5.7 \mathrm{mM})$ solutions were prepared by dissolving with $\mathrm{DI}_{2} \mathrm{O}$ separately. First, $\mathrm{NaOH}$ was dissolved in DI $\mathrm{H}_{2} \mathrm{O}$ under magnetic stirring for 10 min. EDA was then added to $\mathrm{NaOH}$ solution under magnetic stirring for $2 \mathrm{~min}$. In this process, the solution is kept colorless. At the end of $2 \mathrm{~min}, \mathrm{CuCl}_{2}$ solution was added to the colorless solution. The addition of $\mathrm{CuCl}_{2}$ solution turned light blue and then dark blue at the end of $10 \mathrm{~min}$ due to $\mathrm{CuCl}_{2}$ decomposition, as shown in Equation (1):

$$
2 \mathrm{NaOH}(\mathrm{aq})+\mathrm{CuCl}_{2}(\mathrm{aq}) \rightarrow \mathrm{Cu}(\mathrm{OH})_{2}(\mathrm{aq})+2 \mathrm{NaCl}
$$

At the end of $10 \mathrm{~min}, \mathrm{~N}_{2} \mathrm{H}_{4}$ was added to the dark blue solution. Copper hydroxide $\left(\mathrm{Cu}(\mathrm{OH})_{2}\right)$ was decomposed to copper oxide $\left(\mathrm{Cu}_{2} \mathrm{O}\right)$ by adding $\mathrm{N}_{2} \mathrm{H}_{4}$ through Equation (2), and $\mathrm{Cu}_{2} \mathrm{O}$ nanoparticles were further reduced to copper seeds through Equation (3):

$$
\mathrm{Cu}(\mathrm{OH})_{2}(\mathrm{aq})+\mathrm{N}_{2} \mathrm{H}_{4}(\mathrm{aq}) \rightarrow 2 \mathrm{Cu}_{2} \mathrm{O}(\mathrm{s})+\mathrm{H}_{2} \mathrm{O}
$$




$$
2 \mathrm{Cu}_{2} \mathrm{O}(\mathrm{s})+\mathrm{N}_{2} \mathrm{H}_{4}(\mathrm{aq}) \rightarrow 4 \mathrm{Cu}(\mathrm{s})+\mathrm{N}_{2}(\mathrm{~g})+2 \mathrm{H}_{2} \mathrm{O}
$$

Copper seeds produced in Equation (3) then grew into copper nanowires with continuous heating under magnetic stirring. As soon as $\mathrm{N}_{2} \mathrm{H}_{4}$ was added, the dark blue solution turned white and then turned reddish-brown after $2 \mathrm{~h}$ of reaction time. At the end of $2 \mathrm{~h}$ of stirring, the copper nanowire solution was washed with methanol to eliminate chemical impurities and dried in a vacuum desiccator at room temperature for at least $2 \mathrm{~h}$.

\subsection{Method for Fabrication of Cu-Ag Nanowires}

$\mathrm{Cu}-\mathrm{Ag}$ nanowires were fabricated by a new green method, adding $\mathrm{DMSO}_{2}$ at room temperature without electrodes and heating. This process was conducted under $300 \mathrm{rpm}$ magnetic stirring to reach a homogenous state. First, $1 \mathrm{wt} \%$ of $\mathrm{DMSO}_{2}$ and $1 \mathrm{mM}$ of $\mathrm{AgNO}_{3}$ solution were prepared in an Erlenmeyer flask separately under magnetic stirring. Then, $1 \mathrm{wt} \%$ of $\mathrm{DMSO}_{2}$ was added to well-dispersed copper nanowire solution (from the previous section) under magnetic stirring for $5 \mathrm{~min}$, and then $\mathrm{AgNO}_{3}$ solution was added at the end of $5 \mathrm{~min}$. When $\mathrm{AgNO}_{3}$ solution was added, the solution gradually turned from reddish-brown to gray. During the 10 min reaction time, the solution turned dark gray. At the end of $10 \mathrm{~min}$, the $\mathrm{Cu}-\mathrm{Ag}$ nanowire solution was washed with methanol and dried in a vacuum desiccator at room temperature for at least $2 \mathrm{~h}$.

\subsection{Characterization}

To characterize bulk copper nanowires and $\mathrm{Cu}-\mathrm{Ag}$ nanowires, scanning electron microscopy (SEM, Helios 400, FEI, Hillsboro, OR, USA) with an accelerating voltage of $5 \mathrm{kV}$ was utilized. The morphology and dimensions including the length and diameter of copper nanowires and $\mathrm{Cu}-\mathrm{Ag}$ nanowires were observed by transmission electron microscopy (TEM, Tecnai F-20, FEI, Hillsboro, OR, USA) with an accelerating voltage of $200 \mathrm{kV}$. Energy-dispersive X-ray spectroscopy (EDX)was used for the elemental analysis of $\mathrm{Cu}$-Ag nanowires.

\section{Results and Discussion}

\subsection{The Effect of Concentration of $\mathrm{N}_{2} \mathrm{H}_{4}$}

The concentrations of $\mathrm{NaOH}, \mathrm{EDA}$, and $\mathrm{CuCl}_{2}$ were held constant throughout this study, and the reaction temperature and time were kept at $60{ }^{\circ} \mathrm{C}$ and $2 \mathrm{~h}$, respectively. Copper nanowires were synthesized with different amounts of $1.7 \mathrm{mM}^{\circ} \mathrm{N}_{2} \mathrm{H}_{4}$. Figure 1 indicates the dimension distribution, including length and diameter.

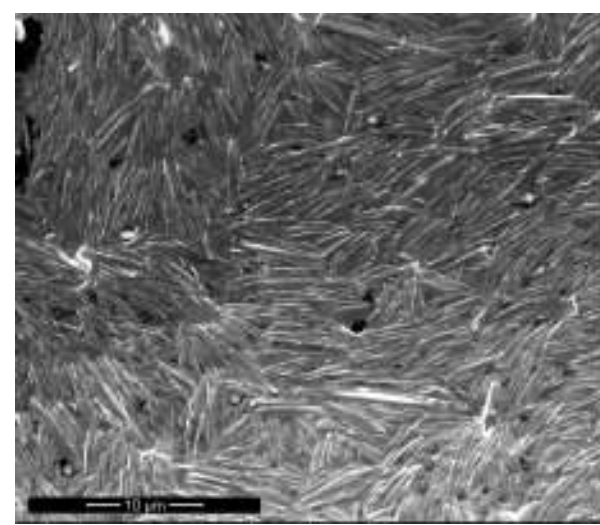

(a)

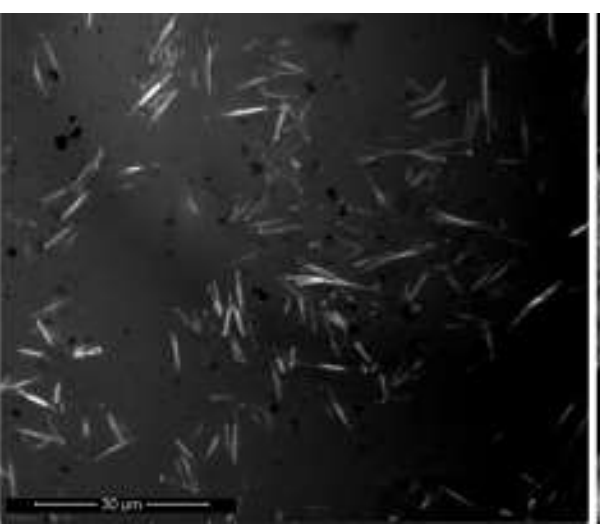

(b)

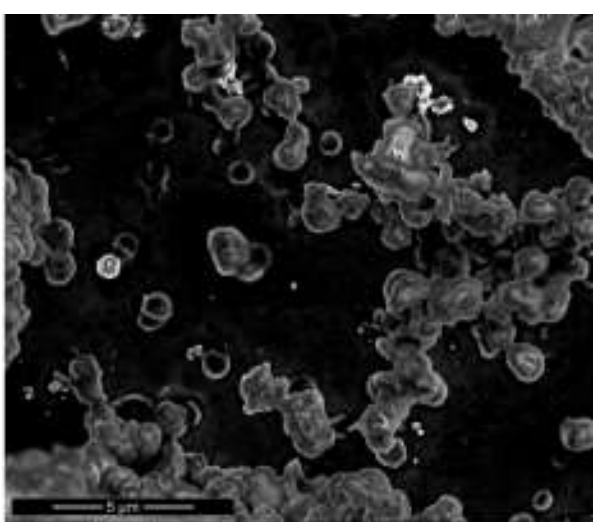

(c)

Figure 1. SEM images of copper nanowires with: (a) $15 \mu \mathrm{L}$; (b) $30 \mu \mathrm{L}$; (c) $240 \mu \mathrm{L}$ of $\mathrm{N}_{2} \mathrm{H}_{4}$. 
By adding $15 \mu \mathrm{L}$ of $\mathrm{N}_{2} \mathrm{H}_{4}$, the synthesized copper nanowires were $4-13 \mu \mathrm{m}$ in length and 250-550 nm in diameter, as shown in Figure 1a. Meanwhile, copper nanowires synthesized with $30 \mu \mathrm{L}$ of $\mathrm{N}_{2} \mathrm{H}_{4}$ were $4-15 \mu \mathrm{m}$ in length and $450-750 \mathrm{~nm}$ in diameter, as shown in Figure 1b. There are no significant differences in dimensions between copper nanowires synthesized with $15 \mu \mathrm{L}$ and $30 \mu \mathrm{L}$ of $\mathrm{N}_{2} \mathrm{H}_{4}$. However, a higher yield of copper nanowires is shown in Figure 1a compared to Figure 1b. Interestingly, copper nanoparticles, which are $800 \mathrm{~nm}$ in diameter, are observed dominantly without copper nanowires, as shown in Figure 1c. Since $\mathrm{N}_{2} \mathrm{H}_{4}$ is a strong reducing agent, the additional amount of $\mathrm{N}_{2} \mathrm{H}_{4}$ increases the diameter of the copper nanowires. However, an excessive amount of $\mathrm{N}_{2} \mathrm{H}_{4}$ causes an imbalance in the process of growing copper nanowires from copper seeds. Therefore, the process may not be completely conducted exhibiting the dominant copper nanoparticles. Table 1 summarizes the dimensions of length and diameter for each copper product synthesized with various amounts of $\mathrm{N}_{2} \mathrm{H}_{4}$.

Table 1. Dimensions of copper nanowires synthesized with various amounts of $\mathrm{N}_{2} \mathrm{H}_{4}$.

\begin{tabular}{ccc}
\hline $\mathbf{N}_{\mathbf{2}} \mathbf{H}_{\mathbf{4}}(\boldsymbol{\mu L})$ & Length $(\boldsymbol{\mu m})$ & Diameter $(\mathbf{n m})$ \\
\hline 15 & $4-13$ & $250-550$ \\
\hline 30 & $4-15$ & $450-750$ \\
\hline 240 & Copper nanoparticles of the diameter of $800 \mathrm{~nm}$ \\
\hline
\end{tabular}

\subsection{The Effect of Temperature on Morphology of Copper Nanowires}

The concentrations of $4.8 \mathrm{M}$ of NaOH, $30 \mu \mathrm{L}$ of EDA, $17 \mathrm{mM}$ of $\mathrm{CuCl}_{2}$, and $5.7 \mathrm{mM}$ of $\mathrm{N}_{2} \mathrm{H}_{4}$ were held constant, and various reaction temperatures $\left(40,50,60,70,80\right.$, and $\left.90^{\circ} \mathrm{C}\right)$ were maintained for a $2 \mathrm{~h}$ reaction time. Figures $2-7$ show copper nanowires synthesized at various reaction temperatures that have different morphology and dimensions. As shown in Figure 2a, copper nanowires synthesized at $40{ }^{\circ} \mathrm{C}$ show the aggregation of copper products, which makes it difficult to grow copper nanowires. In addition, the surfaces are not smooth, with some dented areas in Figure $2 \mathrm{~b}$. Copper nanowires measure more than $3.5 \mu \mathrm{m}$ in length and $130-250 \mathrm{~nm}$ in diameter. The aggregation of copper products is slightly reduced at a higher reaction temperature of $50^{\circ} \mathrm{C}$, but the surfaces of copper nanowires are still rough, as shown in Figure 3. Copper nanowires synthesized at $50{ }^{\circ} \mathrm{C}$ measure more than $5 \mu \mathrm{m}$ in length and $130-280 \mathrm{~nm}$ in diameter. Figure 4a shows that there is a greater reduction in copper aggregation synthesized at $60^{\circ} \mathrm{C}$ than 40 or $50^{\circ} \mathrm{C}$. In addition, Figure $4 \mathrm{~b}$ shows that the copper nanowires measure more than $8 \mu \mathrm{m}$ in length and $200-310 \mathrm{~nm}$ in diameter. Interestingly, as the reaction temperature is increased to $70^{\circ} \mathrm{C}$, the smoothness of the surface is significantly improved without the aggregation of copper products, as shown in Figure 5. Copper nanowires synthesized at $70^{\circ} \mathrm{C}$ measure more than $5 \mu \mathrm{m}$ in length and $210-260 \mathrm{~nm}$ in diameter.

Copper nanowires synthesized at $80{ }^{\circ} \mathrm{C}$ measure more than $6 \mu \mathrm{m}$ in length and $120-280 \mathrm{~nm}$ in diameter. At this temperature, copper nanowires start to have kinks at the end, as shown in Figure 6a. The kinks may degrade the physical properties of the copper nanowires, including electrical and thermal conductivity, since there is a reduction in the cross-sectional area due to the kinks. With a further increased reaction temperature to $90^{\circ} \mathrm{C}$, copper products display oxidation, as shown in Figure 7. This is because the oxidation of copper is accelerated by a higher reaction temperature.

Table 2 summarizes the dimensions of the copper nanowires synthesized at various temperatures. It can be seen that there is no tendency to become greater in length and thinner in diameter as the reaction temperature is increased. However, the reaction temperature affects the formation of copper seeds and growth of copper nanowires. 


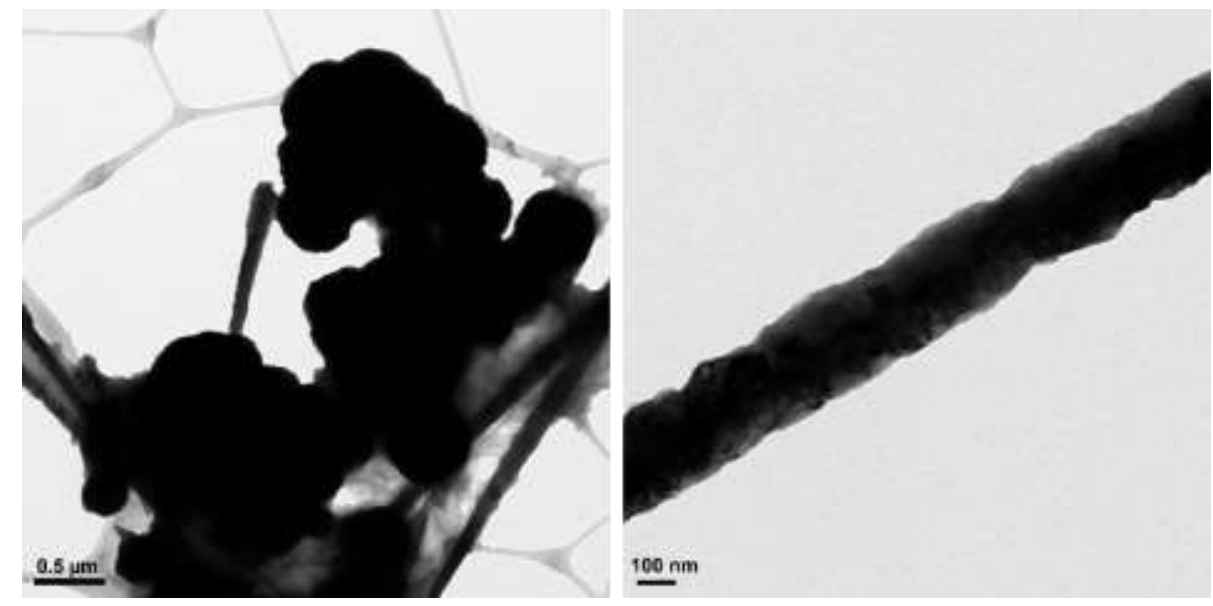

(a)

(b)

Figure 2. TEM images of copper products at $40^{\circ} \mathrm{C}$ : (a) scale bar $0.5 \mu \mathrm{m}$; (b) scale bar $100 \mathrm{~nm}$.

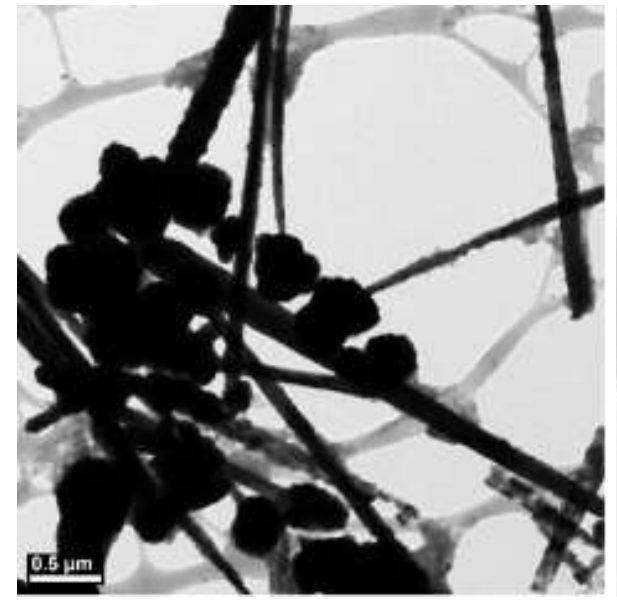

(a)

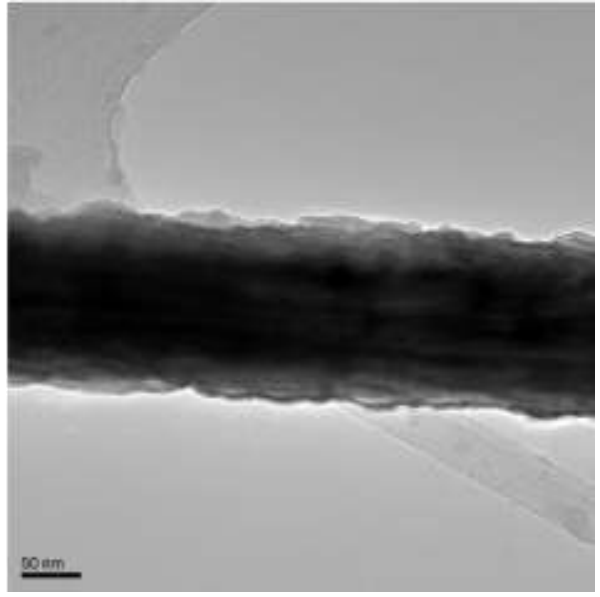

(b)

Figure 3. TEM images of copper products at $50{ }^{\circ} \mathrm{C}$ : (a) scale bar $0.5 \mu \mathrm{m}$; (b) scale bar $50 \mathrm{~nm}$.

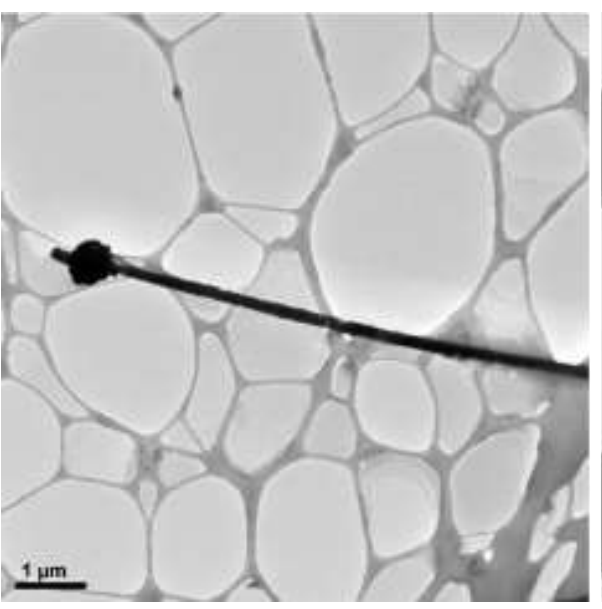

(a)

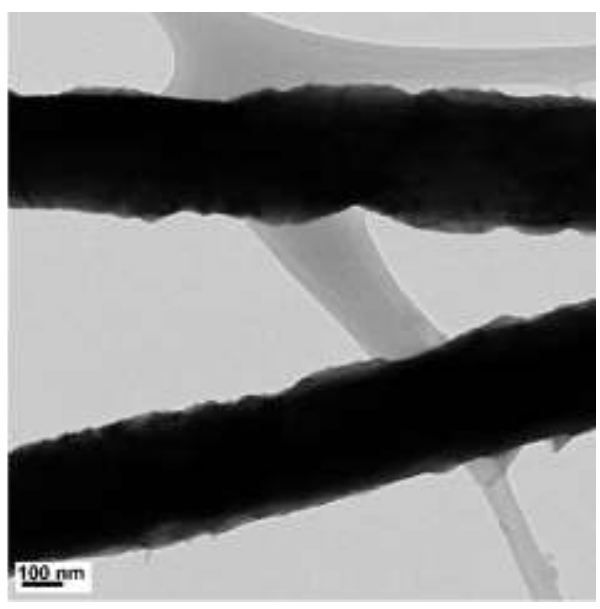

(b)

Figure 4. TEM images of copper products at $60^{\circ} \mathrm{C}$ : (a) scale bar $1 \mu \mathrm{m}$; (b) scale bar $100 \mathrm{~nm}$. 


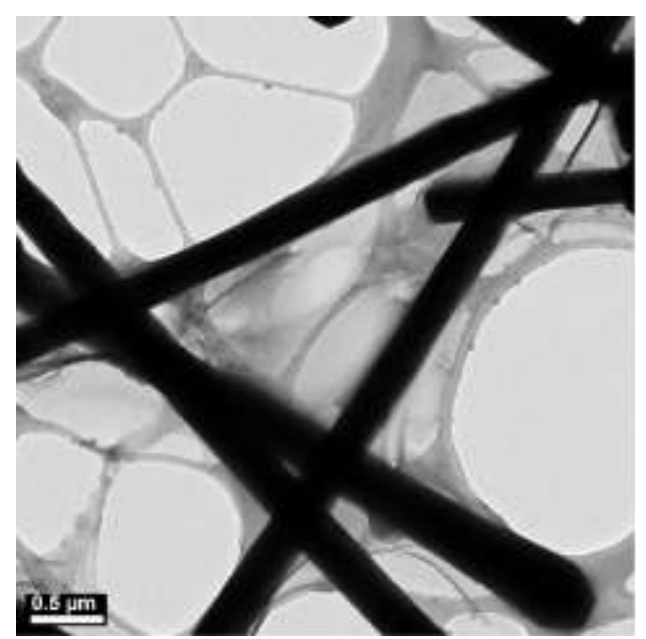

(a)

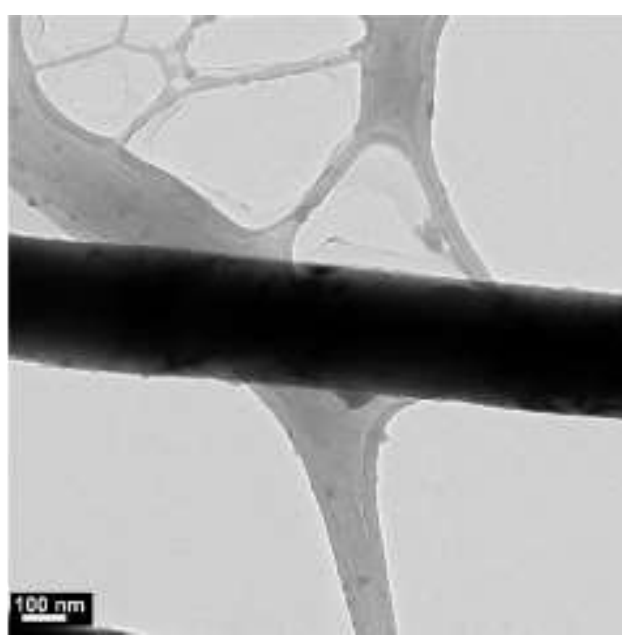

(b)

Figure 5. TEM images of copper products at $70^{\circ} \mathrm{C}$ : (a) scale bar $0.5 \mu \mathrm{m}$; (b) scale bar $100 \mathrm{~nm}$.

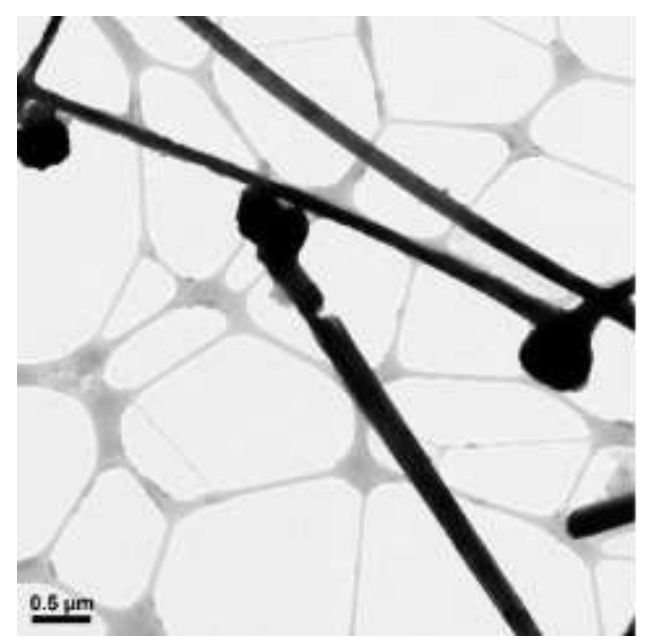

(a)

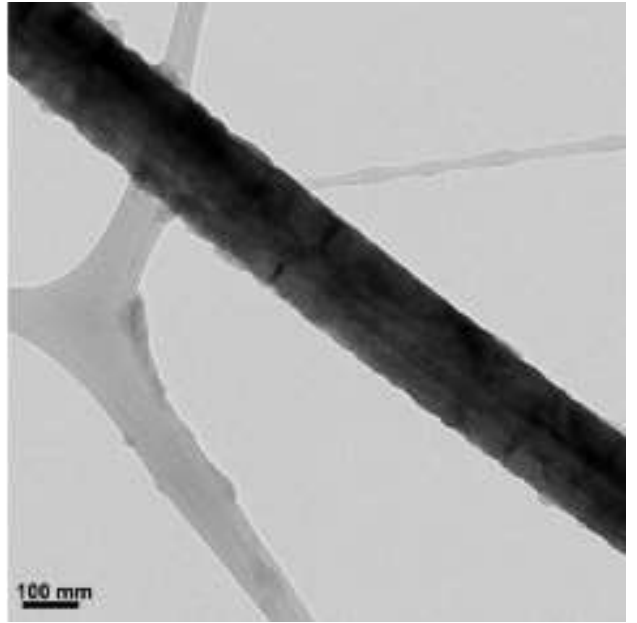

(b)

Figure 6. TEM images of copper products at $80{ }^{\circ} \mathrm{C}$ : (a) scale bar $0.5 \mu \mathrm{m}$; (b) scale bar $100 \mathrm{~nm}$.

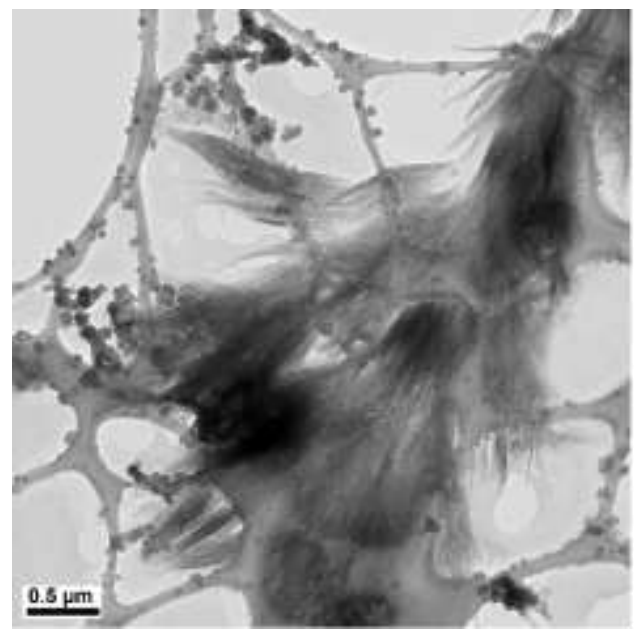

Figure 7. TEM images of copper products at $90{ }^{\circ} \mathrm{C}$ (scale bar $\left.0.5 \mu \mathrm{m}\right)$. 
Table 2. Dimensions of copper products synthesized at various reaction temperatures.

\begin{tabular}{ccc}
\hline Reaction Temperature $\left({ }^{\circ} \mathbf{C}\right)$ & Length $(\boldsymbol{\mu m})$ & Diameter $(\mathbf{n m})$ \\
\hline 40 & more than 3.5 & $130-250$ \\
\hline 50 & more than 5 & $130-280$ \\
\hline 60 & more than 8 & $200-310$ \\
\hline 70 & more than 5 & $210-260$ \\
\hline 80 & more than 6 & $120-280$ \\
\hline 90 & The oxidation of copper nanowires \\
\hline
\end{tabular}

Based on the aggregation of copper products and the morphology of copper nanowires, EDA as a capping agent is affected by the reaction temperatures since the capping agent prevents precipitation and aggregation by protecting the surface of copper seeds. To protect the surface of copper seeds, the reaction temperature of at least $60{ }^{\circ} \mathrm{C}$, at which the aggregations are not observed, is required. However, EDA may perform actively at $70{ }^{\circ} \mathrm{C}$ to obtain a smooth surface without the aggregation of the copper products by providing sufficient surface energy.

\subsection{The Effect of Concentration of EDA}

The concentrations of $14.7 \mathrm{M}$ of $\mathrm{NaOH}, 17 \mathrm{mM}$ of $\mathrm{CuCl}_{2}$, and $5.7 \mathrm{mM}$ of $\mathrm{N}_{2} \mathrm{H}_{4}$ were held constant, and the reaction temperature and time were kept at $70{ }^{\circ} \mathrm{C}$ and $2 \mathrm{~h}$, respectively. Copper nanowires were formed at various concentrations of $\operatorname{EDA}(15,50$, and $60 \mu \mathrm{L})$, as shown in Figures 8-10. Copper nanowires synthesized by adding $15 \mu \mathrm{L}$ of EDA measure more than $4 \mu \mathrm{m}$ in length and $250-550 \mathrm{~nm}$ in diameter, as shown in Figure 8. A few copper seeds and irregular surfaces of copper nanowires are observed. The increased amount of EDA to $50 \mu \mathrm{L}$ dominantly forms the tapered copper nanowires, as shown in Figure 9. The tapered copper nanowires could result from the unstably protected surface of copper seeds that makes it difficult to grow copper nanowires. Copper nanowires synthesized with $50 \mu \mathrm{L}$ of EDA measure more than $2 \mu \mathrm{m}$ in length and $210-270 \mathrm{~nm}$ in diameter. However, there are no copper seeds, and the surface of copper nanowires is quite smooth. With the further increased amount of EDA to $60 \mu \mathrm{L}$, the synthesized copper nanowires measure more than $6 \mu \mathrm{m}$ in length and 130-170 $\mu \mathrm{m}$ in diameter. However, very small nanoparticles are observed on the surface of copper nanowires, as shown in Figure 10. The surface and morphology of copper nanowires are affected by the amounts of EDA. The addition of EDA does not guarantee the protection of the surface of copper seeds completely. However, EDA may control the dimensions of copper nanowires depending on the amount. An excessive amount of EDA erratically protects copper seeds, resulting in the irregular surface of copper nanowires. The irregular surface can generate defects in copper nanowires, including a dangling bond that is significantly sensitive to ambient conditions where copper nanowires can be oxidized. Table 3 summarizes the size distribution for each set of copper nanowires synthesized under various amounts of EDA.

\subsection{The Effect of Concentration of $\mathrm{NaOH}$}

The concentrations of $50 \mu \mathrm{L}$ of EDA, $17.1 \mathrm{mM}$ of $\mathrm{CuCl}_{2}$, and $5.7 \mathrm{mM}$ of $\mathrm{N}_{2} \mathrm{H}_{4}$ were held constant, and the reaction temperature and time were preserved at $70{ }^{\circ} \mathrm{C}$ and $2 \mathrm{~h}$, respectively. Copper nanowires were synthesized under various concentrations of $\mathrm{NaOH}$ $(5,7,9$, and $12 \mathrm{M})$. Figure 11 shows the copper nanowires synthesized with $5 \mathrm{M} \mathrm{NaOH}$, indicating similar morphology as Figure 9, which shows copper wires synthesized with 14.7 M of NaOH. Copper nanowires more than $3 \mu \mathrm{m}$ in length and 130-250 $\mathrm{nm}$ in diameter are observed in Figure 11. As shown in Figure 12, synthesized copper nanowires more than $12 \mu \mathrm{m}$ in length and $80-160 \mathrm{~nm}$ in diameter are developed with a higher concentration of $\mathrm{NaOH}$. However, there are some aggregations of copper seeds. The ultra-long and ultra-thin copper nanowires synthesized with $9 \mathrm{M}$ of $\mathrm{NaOH}$ measure more than $18 \mu \mathrm{m}$ in 
length and 25-45 $\mathrm{nm}$ in diameter, as shown in Figure 13. The dimensions are remarkably developed compared to 5 and $7 \mathrm{M}$ of $\mathrm{NaOH}$, as shown in Figures 11 and 12, respectively. Copper nanowires begin to float on the top of the solution due to the high density of the solution without the centrifugation process. Moreover, a high yield of copper nanowires is obtained, as shown in Figure 14. The further increased concentration of $\mathrm{NaOH}$ to $12 \mathrm{M}$ indicates the aggregation of copper seeds and a fivefold difference in the diameter, as shown in Figure 15.

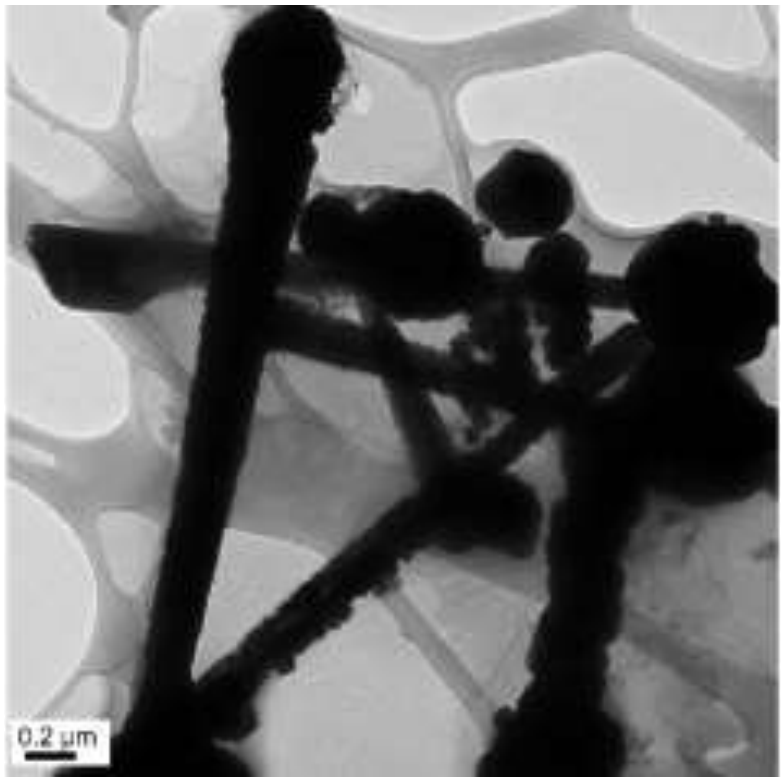

(a)

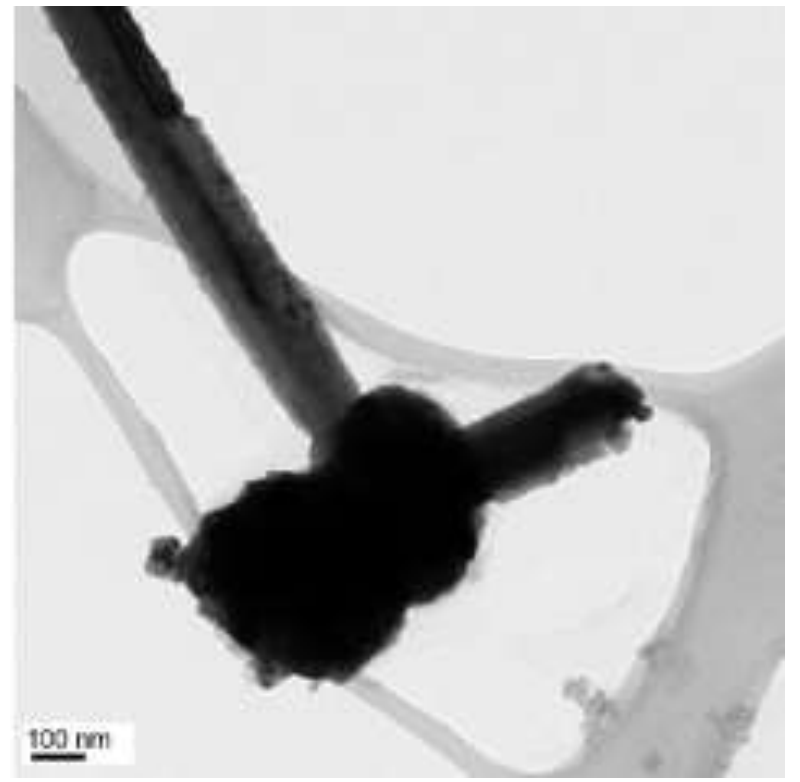

(b)

Figure 8. TEM images of copper nanowires with $15 \mu \mathrm{L}$ of EDA: (a) scale bar $0.2 \mu \mathrm{m}$; (b) scale bar $100 \mathrm{~nm}$.

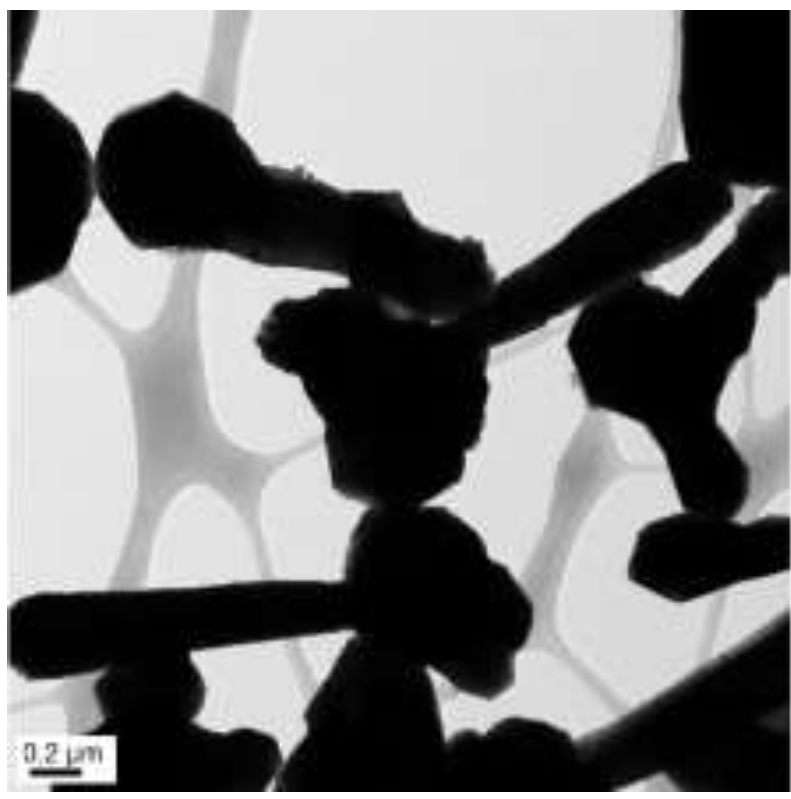

Figure 9. TEM images of copper nanowires with $50 \mu \mathrm{L}$ of EDA (scale bar $0.2 \mu \mathrm{m}$ ). 


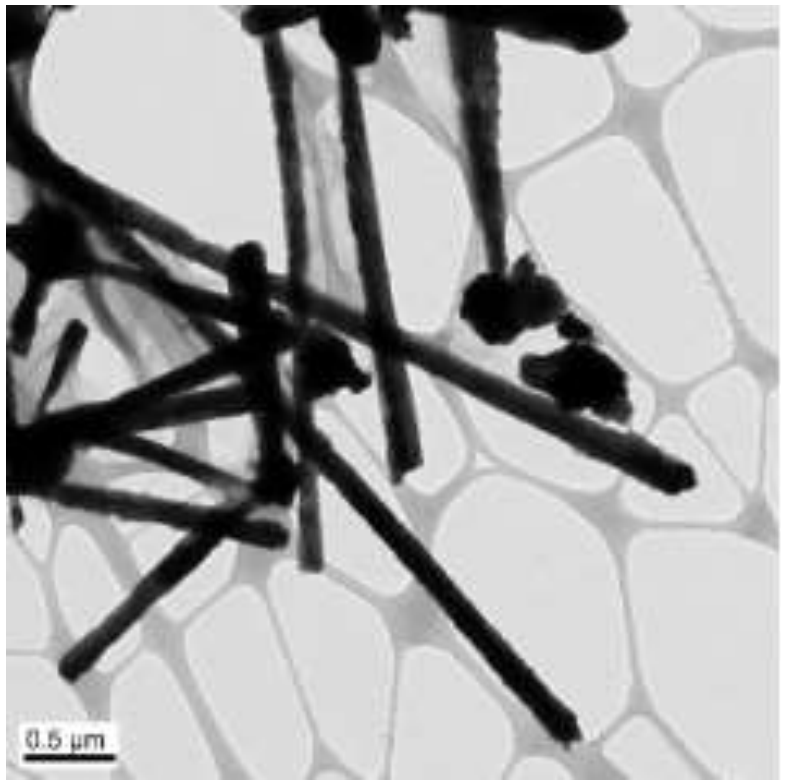

(a)

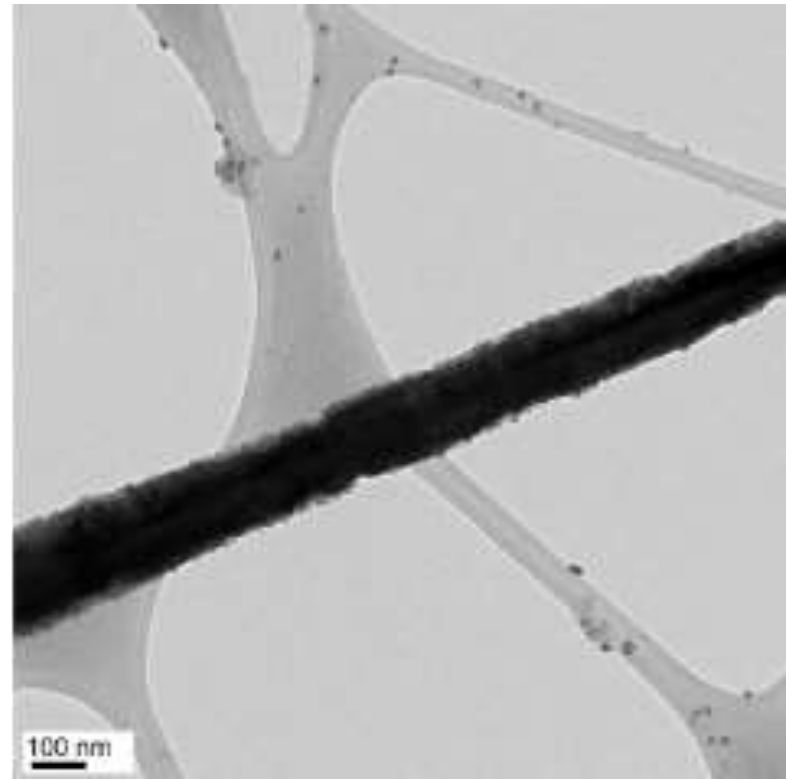

(b)

Figure 10. TEM images of copper nanowires with $50 \mu \mathrm{L}$ of EDA: (a) scale bar $0.5 \mu \mathrm{m}$; (b) scale bar $100 \mathrm{~nm}$.

Table 3. Dimensions of copper nanowires synthesized under various amounts of EDA.

\begin{tabular}{ccc}
\hline EDA & Length $(\mu \mathrm{m})$ & Diameter $(\mathbf{n m})$ \\
\hline 15 & more than 4 & $150-220$ \\
\hline 50 & more than 2 & $210-270$ \\
\hline 60 & more than 6 & $130-170$ \\
\hline
\end{tabular}

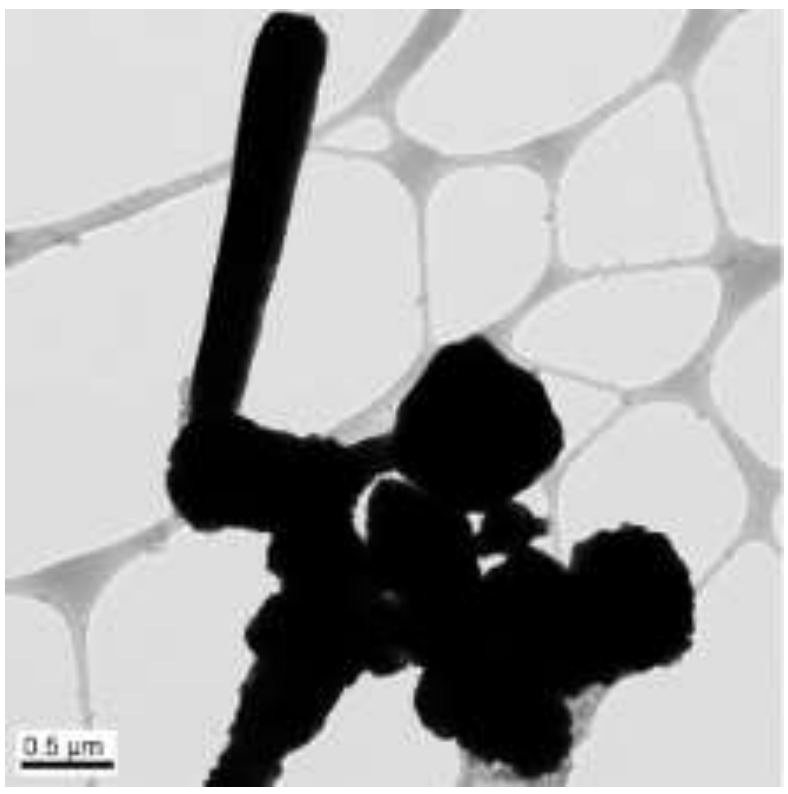

Figure 11. TEM images of copper nanowires with $5 \mathrm{M}$ of $\mathrm{NaOH}$ (scale bar $0.5 \mu \mathrm{m}$ ). 


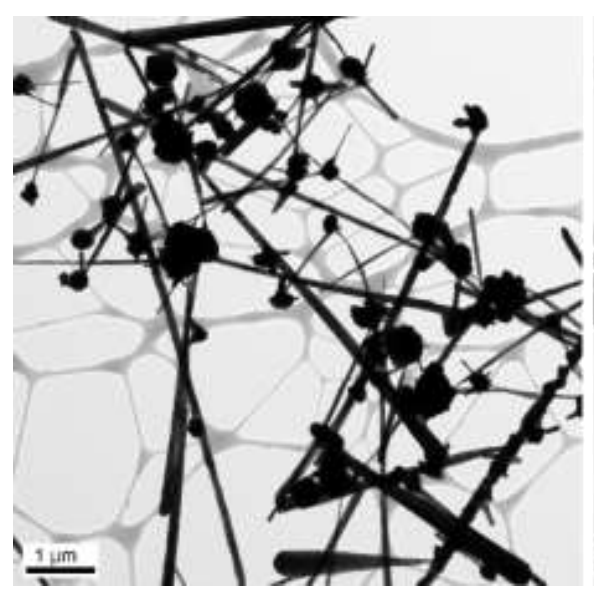

(a)

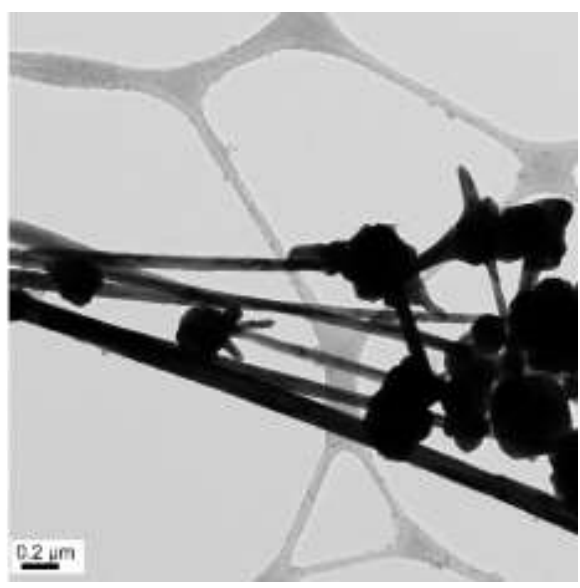

(b)

Figure 12. TEM images of copper nanowires with $7 \mathrm{M}$ of $\mathrm{NaOH}$ : (a) scale bar $1 \mu \mathrm{m}$; (b) scale bar $0.2 \mu \mathrm{m}$.

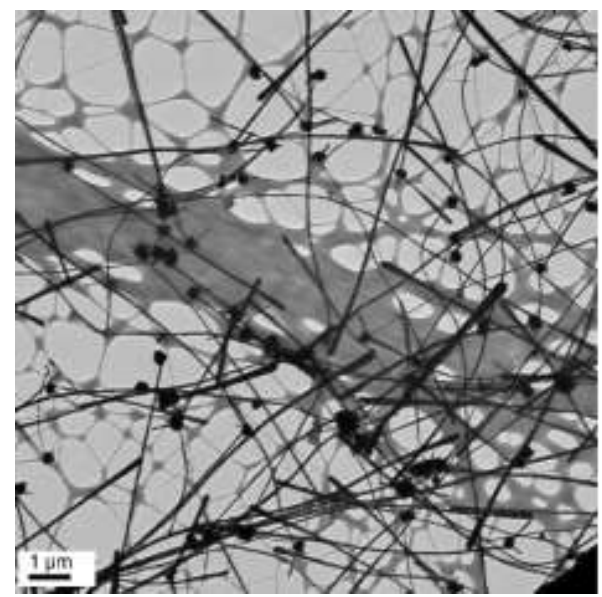

(a)

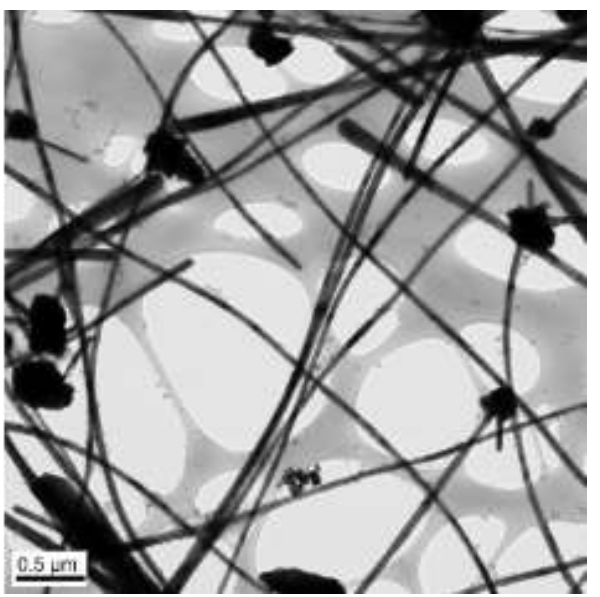

(b)

Figure 13. TEM images of copper nanowires with $9 \mathrm{M}$ of $\mathrm{NaOH}$ : (a) scale bar $1 \mu \mathrm{m}$; (b) scale bar $0.5 \mu \mathrm{m}$.

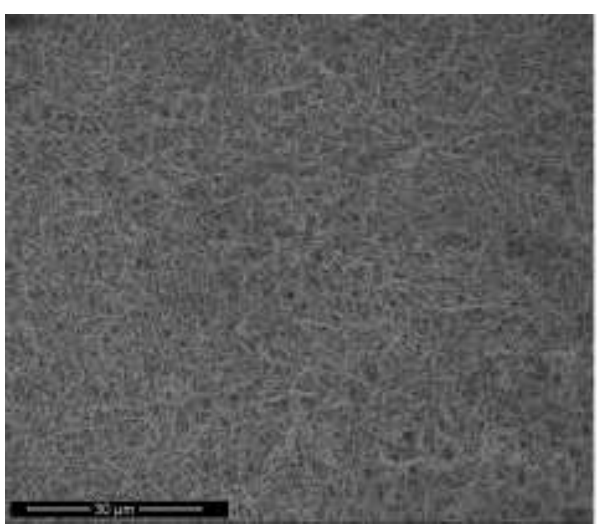

(a)

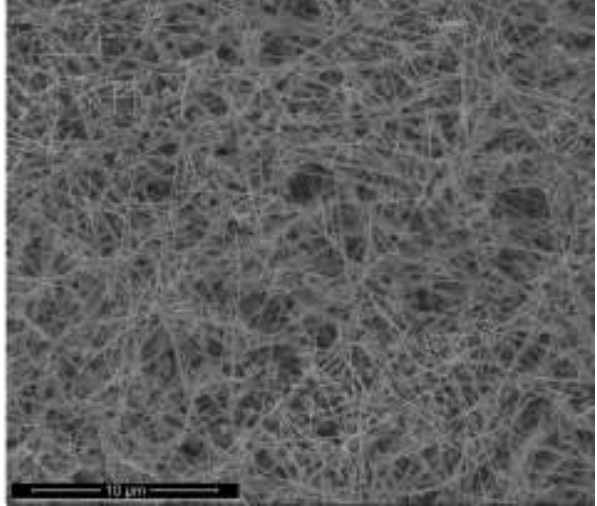

(b)

Figure 14. SEM images of copper nanowires with $9 \mathrm{M}$ of $\mathrm{NaOH}$ : (a) scale bar $30 \mu \mathrm{m}$; (b) scale bar $10 \mu \mathrm{m}$. 


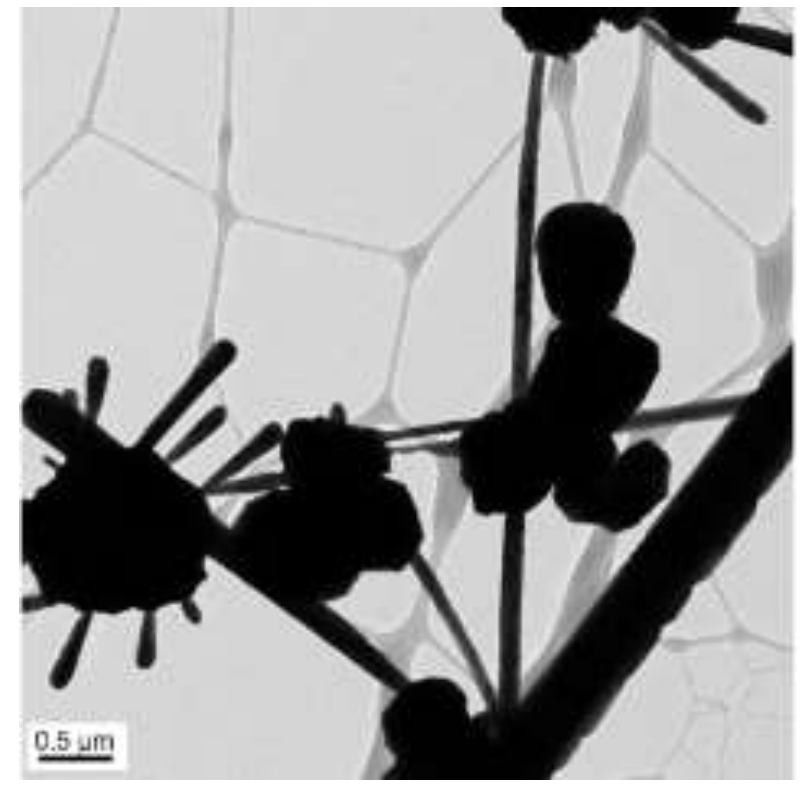

(a)

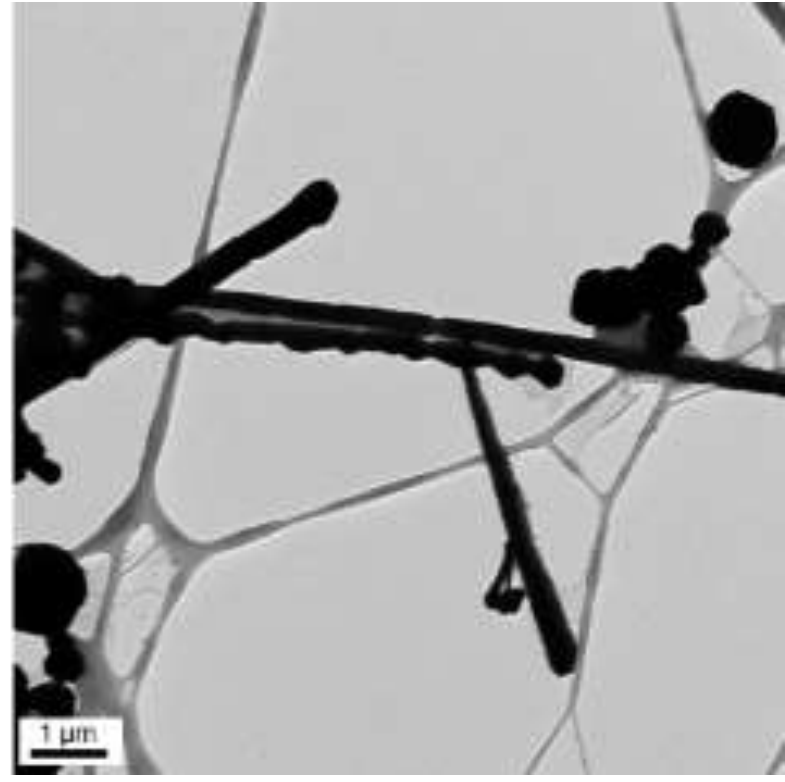

(b)

Figure 15. TEM images of copper nanowires with $12 \mathrm{M}$ of $\mathrm{NaOH}$ : (a) scale bar $0.5 \mu \mathrm{m}$; (b) scale bar $1 \mu \mathrm{m}$.

The high concentration of $\mathrm{NaOH}$ above $9 \mathrm{M}$ causes the incomplete formation of copper nanowires. This is because a high concentration of $\mathrm{NaOH}$ could not be completely dissolved in $\mathrm{DI}_{2} \mathrm{O}$, and the remaining $\mathrm{NaOH}$ may prevent copper seeds from being protected by EDA. The low concentration of $\mathrm{NaOH}$ below $9 \mathrm{M}$ is likely required to increase the amount of EDA to improve the aggregation of copper seeds. This means that $\mathrm{NaOH}$ interplays with EDA. Therefore, the complete formation of copper nanowires can be affected by controlling the concentration of $\mathrm{NaOH}$ and EDA simultaneously. Table 4 summarizes the dimensions of copper nanowires.

Table 4. Dimensions of copper nanowires synthesized under the various concentrations of $\mathrm{NaOH}$.

\begin{tabular}{ccc}
\hline $\mathbf{N a O H}(\mathbf{M})$ & Length $(\mu \mathrm{m})$ & Diameter $(\mathbf{n m})$ \\
\hline 5 & more than 3 & $130-250$ \\
\hline 7 & more than 12 & $80-160$ \\
\hline 9 & more than 18 & $25-45$ \\
\hline 12 & more than 12 & $100-500$ \\
\hline
\end{tabular}

\subsection{The Effect of Concentration of Copper Precursor}

The concentrations of $9 \mathrm{M}$ of $\mathrm{NaOH}, 50 \mu \mathrm{L}$ of EDA, and $5.7 \mathrm{mM}$ of $\mathrm{N}_{2} \mathrm{H}_{4}$ were held constant, and the reaction temperature and time were $70{ }^{\circ} \mathrm{C}$ and $2 \mathrm{~h}$, respectively. Copper nanowires were synthesized by adding the concentration of $37 \mathrm{mM}$ of $\mathrm{CuCl}_{2}$. Compared to Figure 13, doubling the concentration of $\mathrm{CuCl}_{2}$ produces thicker and shorter nanowires with dimensions more than $6 \mu \mathrm{m}$ in length and 100-240 $\mathrm{nm}$ in diameter. In addition, the increased concentration of copper precursor causes large aggregations of copper seeds, as shown in Figure 16. This is because EDA cannot protect the surface of copper seeds. These copper seeds may begin to agglomerate and make it difficult to grow copper nanowires. Therefore, the amount of EDA must be adjusted depending on the concentration of copper precursor. 


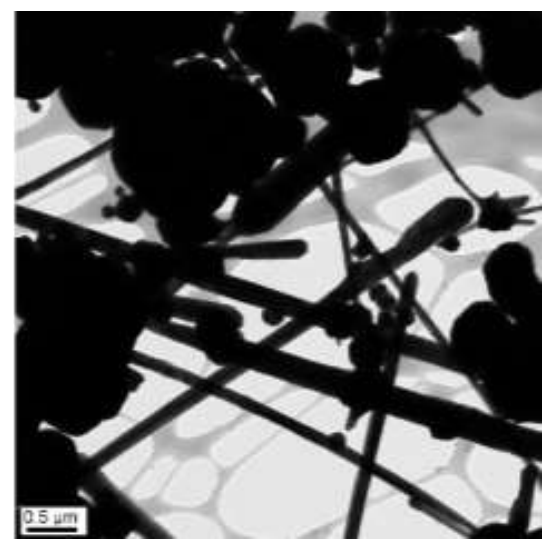

Figure 16. TEM image of copper nanowires with $37 \mathrm{mM}$ of copper precursor (scale bar $0.5 \mu \mathrm{m}$ ).

\subsection{Fabrication of $\mathrm{Cu}-\mathrm{Ag}$ Nanowires}

Silver coating on the surface of copper nanowires is induced by a redox reaction between copper and silver through Equation (4):

$$
\begin{array}{cc}
\mathrm{Cu} \rightarrow \mathrm{Cu}^{2+}+2 \mathrm{e}^{-} & \mathrm{E}^{0}=-0.3419 \mathrm{~V} \\
\mathrm{Ag}^{+}+\mathrm{e}^{-} \rightarrow \mathrm{Ag} & \mathrm{E}^{0}=+0.7996 \mathrm{~V} \\
\mathrm{Cu}^{2+}+2 \mathrm{Ag}^{+} \rightarrow \mathrm{Cu}^{2+}+2 \mathrm{Ag} \downarrow & \Delta \mathrm{E}^{0}=+0.4577 \mathrm{~V}
\end{array}
$$

The redox reaction between copper and silver occurs spontaneously due to the positive difference redox potential $\left(\Delta \mathrm{E}^{0}\right)$ of $+0.4577 \mathrm{~V}$. Herein, $\mathrm{DMSO}_{2}$ could act as a silver reductant and a copper surfactant. When $\mathrm{DMSO}_{2}$ is added to the copper nanowire solution, copper atoms on the surface of the copper nanowires are oxidized to the copper ion state while protecting the surface of copper nanowires from reacting with other reagents. Upon introducing silver ions into the reaction solution, the surface of copper nanowires is coated by a redox reaction. As shown in Figure 17, silver is coated on the surfaces of copper nanowires. Figure 18a shows that the morphology of $\mathrm{Cu}-\mathrm{Ag}$ nanowires includes slightly rough surfaces due to the formation of the silver shell. Figure $18 \mathrm{~b}, \mathrm{c}$ indicate the elemental composition of $\mathrm{Cu}-\mathrm{Ag}$ nanowires obtained by EDX mapping. Figure $18 \mathrm{~b}$ shows that copper is distributed throughout the nanowires, while Figure 18c shows that silver is strongly distributed on the surfaces of the copper nanowires. Fabricated $\mathrm{Cu}-\mathrm{Ag}$ nanowires have a $90 \mathrm{~nm}$ copper core and a $12 \mathrm{~nm}$ thick silver shell. To prevent oxidation, the silver shell is required to be at least $5 \mathrm{~nm}$ thick, and a $15 \mathrm{~nm}$ thick silver shell protects against oxidation in humid conditions [33]. Therefore, a $12 \mathrm{~nm}$ thick silver shell not only could prevent the oxidation of copper nanowires, but also maintain suitable electrical or thermal conductivity that can compete with silver nanowires.

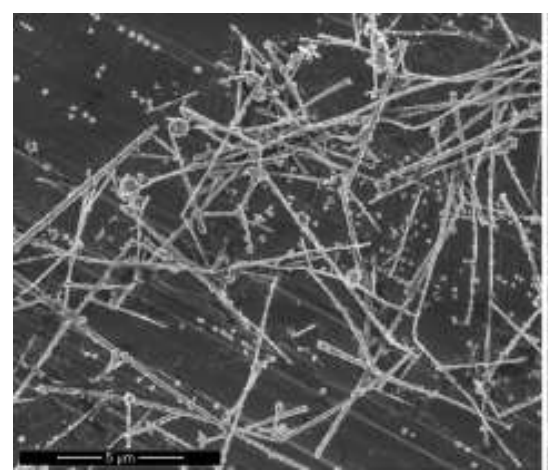

(a)

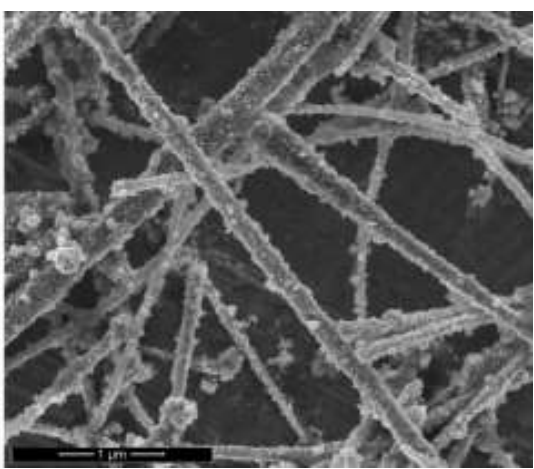

(b)

Figure 17. SEM images of Cu-Ag nanowires: (a) scale bar $5 \mu \mathrm{m}$; (b) $1 \mu \mathrm{m}$. 


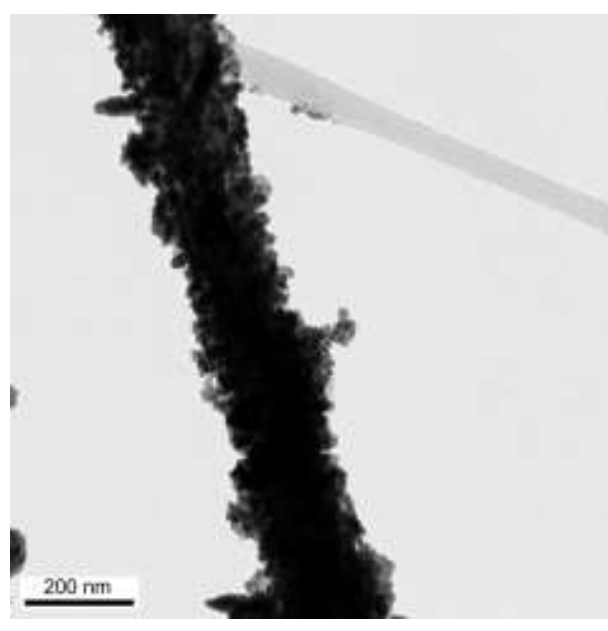

(a)

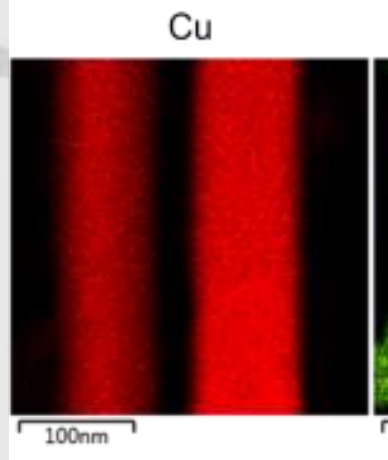

(b)

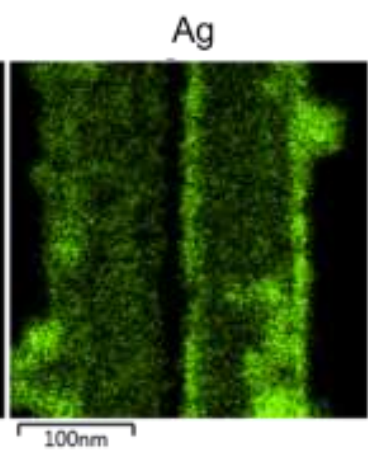

(c)

Figure 18. (a) TEM image of $\mathrm{Cu}-\mathrm{Ag}$ nanowires; EDX mapping element (b) $\mathrm{Cu}$; (c) $\mathrm{Ag}$.

\section{Conclusions}

In conclusion, the morphology of copper nanowires was investigated by adding various concentrations of a reducing agent, a capping agent, a reagent, and a copper precursor, and various reaction temperatures. An excessive amount of $\mathrm{N}_{2} \mathrm{H}_{4}$ not only increased the diameter of copper nanowires but also caused an incomplete process of forming the dominant copper nanoparticles. At least $60{ }^{\circ} \mathrm{C}$ was required to prevent aggregations of copper seeds. However, as EDA performed actively at $70^{\circ} \mathrm{C}$, a smooth surface without aggregations of copper nanowires was observed. In addition, the amount of EDA was controlled to prevent the aggregation of copper seeds. An excessive amount of EDA erratically protected copper seeds and resulted in the irregular surface of copper nanowires. Therefore, it is required to interplay with $\mathrm{NaOH}$ and $\mathrm{CuCl}_{2}$. Copper nanowires synthesized under $9 \mathrm{M}$ of $\mathrm{NaOH}, 50 \mu \mathrm{L}$ of EDA, $17 \mathrm{mM}$ of $\mathrm{CuCl}_{2}$, and $5.7 \mathrm{mM}$ of $\mathrm{N}_{2} \mathrm{H}_{4}$ at a reaction temperature of $70{ }^{\circ} \mathrm{C}$ measured more than $18 \mu \mathrm{m}$ in length and $25-45 \mathrm{~nm}$ in diameter without the aggregation of copper seeds. Cu-Ag nanowires were successfully fabricated by a new green method using $\mathrm{DMSO}_{2}$, which has not been reported previously for the fabrication of core-shell nanowires. $\mathrm{DMSO}_{2}$ acted as a copper surfactant and a silver reductant to initiate a redox reaction while protecting copper ions on the surfaces. The EDX mapping element exhibited the presence of a silver shell on the surface of copper nanowires. Fabricated $\mathrm{Cu}-\mathrm{Ag}$ nanowires had a $90 \mathrm{~nm}$ copper core and a $12 \mathrm{~nm}$ thick silver shell. A silver shell $12 \mathrm{~nm}$ thick could prevent the oxidation of copper nanowires and maintain suitable electrical or thermal properties. In this study, we focused on the synthesis of copper nanowires depending on various conditions, and developed a new green method for the fabrication of $\mathrm{Cu}$-Ag nanowires. For future work, phase characterization and the material properties, including electrical conductivity and thermal stability, should be studied.

Author Contributions: Conceptualization, S.L., C.W. and S.Y.; methodology, S.L., C.W. and S.Y.; investigation, S.L., C.W. and S.Y.; writing-original draft preparation, S.L.; writing-review and editing, C.W. and S.Y.; project administration, S.Y. All authors have read and agreed to the published version of the manuscript.

Funding: This research received no external funding.

Institutional Review Board Statement: Not applicable.

Informed Consent Statement: Not applicable.

Data Availability Statement: The data presented in this study are available on request from the corresponding author. 
Conflicts of Interest: The authors declare no conflict of interest.

\section{References}

1. Guo, H.; Lin, N.; Chen, Y.; Wang, Z.; Xie, Q.; Zheng, T.; Gao, N.; Li, S.; Kang, J.; Cai, D.; et al. Copper nanowires as fully transparent conductive electrodes. Sci. Rep. 2013, 3, 2323. [CrossRef] [PubMed]

2. Hwang, C.; An, J.; Choi, B.D.; Kim, K.; Jung, S.W.; Baeg, K.J.; Kim, M.G.; Ok, K.M.; Hong, J. Controlled aqueous synthesis of ultra-long copper nanowires for stretchable transparent conducting electrode. J. Mater. Chem. C 2016, 4, 1441-1447. [CrossRef]

3. Naghdi, S.; Rhee, K.Y.; Hui, D.; Park, S.J. A review of conductive metal nanomaterials as conductive, transparent, and flexible coatings, thin films, and conductive fillers: Different deposition methods and applications. Coatings 2018, 8, 278. [CrossRef]

4. Lee, S.; Wang, S.; Wern, C.; Yi, S. The green synthesis of 2D copper nanosheets and their light absorption. Materials 2021, 14, 1926. [CrossRef]

5. Zhang, D.; Wang, R.; Wen, M.; Weng, D.; Cui, X.; Sun, J.; Li, H.; Lu, Y. Synthesis of ultralong copper nanowires for highperformance transparent electrodes. J. Am. Chem. Soc. 2012, 134, 14283-14286. [CrossRef]

6. Rathmell, A.R.; Wiley, B.J. The synthesis and coating of long, thin copper nanowires to make flexible, transparent conducting films on plastic substrates. Adv. Mater. 2011, 23, 4798-4803. [CrossRef]

7. Hsu, P.C.; Wang, S.; Wu, H.; Narasimhan, V.K.; Kong, D.; Lee, H.R.; Cui, Y. Performance enhancement of metal nanowire transparent conducting electrodes by mesoscale metal wires. Nat. Commun. 2013, 4, 4-2522. [CrossRef]

8. Hu, L.; Wu, H.; Cui, Y. Metal nanogrids, nanowires, and nanofibers for transparent electrodes. MRS Bull. 2011, 36, 760-765. [CrossRef]

9. Cui, F.; Yu, Y.; Dou, L.; Sun, J.; Yang, Q.; Schildknecht, C.; Schierle-Arndt, K.; Yang, P. Synthesis of ultrathin copper nanowires using tris (trimethylsilyl) silane for high-performance and low-haze transparent conductors. Nano Lett. 2015, 15, 7610-7615. [CrossRef]

10. Ding, S.; Tian, Y.; Jiu, J.; Suganuma, K. Highly conductive and transparent copper nanowire electrodes on surface coated flexible and heat-sensitive substrates. RSC Adv. 2018, 8, 2109-2115. [CrossRef]

11. Duong, T.H.; Kim, H.C. A high productivity and speedy synthesis process for copper nanowires via an ethylenediamine-mediated method. Int. Nano Lett. 2017, 7, 165-169. [CrossRef]

12. Ye, S.; Rathmell, A.R.; Stewart, I.E.; Ha, Y.C.; Wilson, A.R.; Chen, Z.; Wiley, B.J. A rapid synthesis of high aspect ratio copper nanowires for high-performance transparent conducting films. Chem. Commun. 2014, 50, 2562-2564. [CrossRef]

13. Choi, H.; Park, S.H. Seedless growth of free-standing copper nanowires by chemical vapor deposition. J. Am. Chem. Soc. 2004, 126, 6248-6249. [CrossRef]

14. Kim, C.; Gu, W.; Briceno, M.; Robertson, I.M.; Choi, H.; Kim, K. Copper Nanowires with a five-twinned structure grown by chemical vapor deposition. Adv. Mater. 2008, 20, 1859-1863. [CrossRef]

15. Haase, D.; Hampel, S.; Leonhardt, A.; Thomas, J.; Mattern, N.; Büchner, B. Facile one-step-synthesis of carbon wrapped copper nanowires by thermal decomposition of Copper (II)-acetylacetonate. Surf. Coat. Technol. 2007, 201, 9184-9188. [CrossRef]

16. Gelves, G.A.; Murakami, Z.T.; Krantz, M.J.; Haber, J.A. Multigram synthesis of copper nanowires using ac electrodeposition into porous aluminium oxide templates. J. Mater. Chem. 2006, 16, 3075-3083. [CrossRef]

17. Pate, J.; Zamora, F.; Watson, S.M.; Wright, N.G.; Horrocks, B.R.; Houlton, A. Solution-based DNA-templating of sub-10 nm conductive copper nanowires. J. Mater. Chem. C 2014, 2, 9265-9273. [CrossRef]

18. Chang, Y.; Lye, M.L.; Zeng, H.C. Large-scale synthesis of high-quality ultralong copper nanowires. Langmuir 2005, 21, 3746-3748. [CrossRef]

19. Rathmell, A.R.; Bergin, S.M.; Hua, Y.L.; Li, Z.Y.; Wiley, B.J. The growth mechanism of copper nanowires and their properties in flexible, transparent conducting films. Adv. Mater. 2010, 22, 3558-3563. [CrossRef]

20. Kumar, D.R.; Woo, K.; Moon, J. Promising wet chemical strategies to synthesize Cu nanowires for emerging electronic applications. Nanoscale 2015, 7, 17195-17210.

21. Li, S.; Chen, Y.; Huang, L.; Pan, D. Large-scale synthesis of well-dispersed copper nanowires in an electric pressure cooker and their application in transparent and conductive networks. Inorg. Chem. 2014, 53, 4440-4444. [CrossRef] [PubMed]

22. Yin, Z.; Lee, C.; Cho, S.; Yoo, J.; Piao, Y.; Kim, Y.S. Facile synthesis of oxidation-resistant copper nanowires toward solutionprocessable, flexible, foldable, and free-standing electrodes. Small 2014, 10, 5047-5052. [CrossRef] [PubMed]

23. Koo, J.; Kwon, S.; Kim, N.R.; Shin, K.; Lee, H.M. Ethylenediamine-enhanced oxidation resistivity of a copper surface during water-based copper nanowire synthesis. J. Phys. Chem. C 2016, 120, 3334-3340. [CrossRef]

24. Wei, Y.; Chen, S.; Lin, Y.; Yang, Z.; Liu, L. Cu-Ag core-shell nanowires for electronic skin with a petal molded microstructure. J. Mater. Chem. C 2015, 3, 9594-9602. [CrossRef]

25. Xu, L.; Yang, Y.; Hu, Z.W.; Yu, S.H. Comparison study on the stability of copper nanowires and their oxidation kinetics in gas and liquid. ACS Nano 2016, 10, 3823-3834. [CrossRef]

26. Luo, X.; Gelves, G.A.; Sundararaj, U.; Luo, J.L. Silver-coated copper nanowires with improved anti-oxidation property as conductive fillers in low-density polyethylene. Can. J. Chem. Eng. 2013, 91, 630-637. [CrossRef]

27. Chen, Z.; Rathmell, A.R.; Ye, S.; Wilson, A.R.; Wiley, B.J. Optically transparent water oxidation catalysts based on copper nanowires. Angew. Chem. 2013, 125, 13953-13956. [CrossRef] 
28. Xia, X.; Wang, Y.; Ruditskiy, A.; Xia, Y. Galvanic replacement: A simple and versatile route to hollow nanostructures with tunable and well-controlled properties. Adv. Mater. 2013, 25, 6313-6333. [CrossRef]

29. Niu, Z.; Cui, F.; Yu, Y.; Becknell, N.; Sun, Y.; Khanarian, G.; Kim, D.; Dou, L.; Dehestani, A.; Schierle-Arndt, K.; et al. Ultrathin epitaxial Cu@ Au core-shell nanowires for stable transparent conductors. J. Am. Chem. Soc. 2017, 139, 7348-7354. [CrossRef]

30. Chen, Z.; Ye, S.; Wilson, A.R.; Ha, Y.C.; Wiley, B.J. Optically transparent hydrogen evolution catalysts made from networks of copper-platinum core-shell nanowires. Energy Environ. Sci. 2014, 7, 1461-1467. [CrossRef]

31. Jiang, Z.; Tian, Y.; Ding, S.; Wen, J.; Wang, C. Facile synthesis of Cu-Ag hybrid nanowires with strong surface-enhanced Raman scattering sensitivity. CrystEngComm 2016, 18, 1200-1206. [CrossRef]

32. Ye, S.; Stewart, I.E.; Chen, Z.; Li, B.; Rathmell, A.R.; Wiley, B.J. How copper nanowires grow and how to control their properties. Acc. Chem. Res. 2016, 49, 442-451. [CrossRef]

33. Stewart, I.E.; Ye, S.; Chen, Z.; Flowers, P.F.; Wiley, B.J. Synthesis of $\mathrm{Cu}-\mathrm{Ag}, \mathrm{Cu}-\mathrm{Au}$, and $\mathrm{Cu}-\mathrm{Pt}$ core-shell nanowires and their use in transparent conducting films. Chem. Mater. 2015, 27, 7788-7794. [CrossRef] 